\title{
From Good Senses to Good Sense: A Link Between Tactile Information Processing and Intelligence
}

\author{
SHU-CHEN LI \\ Max Planck Institute for Human Development, Berlin, Germany \\ MALINA JORDANOVA \\ Bulgarian Academy of Sciences Institute of Psychology, Sofia, Bulgaria \\ ULMAN LINDENBERGER \\ Max Planck Institute for Human Development, Berlin, Germany
}

\begin{abstract}
Since the 1970s there has been an reemerging interest in Galton's (1883) senses-intelligence hypothesis. The essence of this hypothesis is the conceptual link between fine-tuned sensory functioning and superior intellectual ability. Several studies have investigated the sensory-cognitive link within auditory and visual modalities. In this study, the intersystemic relationship between sensory and cognitive functioning was extended to the tactile modality by examining the associations between three measures of tactile information processing and intelligence in a heterogeneous sample of middle-aged adults $(\mathrm{N}=179$; age range $=30-51)$. Two of the three tactile tasks measured discrimination ability (i.e., roughness discrimination and part-whole matching), whereas the third task measured tactile pressure sensitivity. Results from a series of analyses indicate that sensory measures from the tactile modality are at least as highly correlated with intellectual ability $(r=.18$ to .33$)$ as measures of auditory $(r=.15)$ or visual $(r=20)$ acuity. All together, the three tactile measures accounted for $20.8 \%$ of the total variance in intelligence. The two tactile discrimination measures were found to be better predictors of intelligence than measures of simple sensory acuity.
\end{abstract}

Galton (1883) proposed a potential association between intellectual ability and "the avenues of the senses". His original argument was that the more perceptive the senses are of differences, the wider the field upon which an individual's judgment and intelligence can

Direct all correspondence to: Shu-Chen Li, Max Planck Institute for Human Development, Center of Lifespan Psychology, Lentzeallee 94 D-14195 Berlin, GERMANY <shuchen@ mpib-berlin.mpg.de>.

INTELLIGENCE 26(2): 99-122

ISSN: 0160-2896
Copyright $(\odot) 1998$ by Ablex Publishing Corporation All rights of reproduction in any form reserved. 
act. Hence, intelligent individuals owe their advantages to the ability of making fine sensory discriminations (cf. Deary, 1994). Notwithstanding this early proposal, the link between sensory and intellectual functioning has been neglected in most psychometric studies of intelligence. Traditionally, researchers of intelligence have devoted more effort into the development of measurement tools which include indicators of memory, verbal ability, reasoning and other higher-level cognitive functions, rather than into the search for potential causes of individual differences in intelligence.

Recently, however, there has been a reemerging quest for processes and factorseither at the information processing or biological level-that might underlie intelligence (e.g., Eysenck, 1982; Jensen, 1993; Vernon, 1987). Some researchers, therefore, have reconsidered Galton's hypothesis. For instance, in his recent review on sensory discrimination and intelligence, Deary (1994) vindicated Galton's senses-intelligence hypothesis by arguing that early experimental researchers' dismissals of this hypothesis originated mainly from selectively emphasizing disconfirming results from early studies (e.g., Galton, 1883; Sharp, 1898-1899; Wissler, 1901) while neglecting results of moderately positive correlations between sensory and intellectual measures reported at about the same time (e.g., Abelson, 1911; Burt, 1909-1910; Carey, 1914-1915; 1915-1917; Spearman, 1904). Admitting that the sensory measures are clearly inferior to more complex mental tests for the measurement of intelligence, Deary (1994), along with some early researchers such as Spearman (1904) and Burt (1909-1910), argued that the moderate but consistent correlations between simple sensory measures and general mental ability may be of great importance for the theory of intelligence. This defense of a tentative, if not definitive, role of Galton's hypothesis in the research of intelligence corresponds well with the interactive view of sensation and the role it plays in cognitive development that are central to some classical theories of cognition and development (e.g., Gibson, 1969; Herrnstein \& Boring, 1965; Hilgard, 1987; Piaget, 1952). In addition, the more recent information-processing approach to cognition has motivated researchers to examine the relationships between intelligence and experimental tasks involving elementary components of cognitive processing, such as the size of working memory, processing speed, and the ability of sensory discrimination (e.g., Hunt, 1980; Jensen, 1987; Vernon, 1987).

\section{Galton's Hypothesis in Theories of Cognitive Development and Neuropsychologial Tests}

Despite early and sustained neglects, the essence of Galton's senses-intelligence hypothesis has been implicitly conveyed in long-standing theories of cognition and development. For instance, two historical schools of psychology founded at the turn of this century, British empiricism and German elementarism, both have attended to the role of sensory input from the environment in regulating cognitive behavior (Herrnstein \& Boring, 1965; Hilgard, 1987). This dynamic view between sensation and cognition proposed by the two historical schools left its impacts on theories of cognitive development. Later, the sensory-cognitive link was more specifically stressed in classical theories of cognitive development. Piaget (1952) and Gibson (1969) are two prominent examples. Although Piaget and Gibson had opposing views on whether young children, in the course of development, actively construct rules through physical interactions with the environment (Piaget) or passively extract adaptive life-enhancing information through sensory inputs provided by a 
highly structured environment (Gibson), they both analyzed children's actions in terms of sensorimotor organization which is inherently (Gibson) or later becomes (Piaget) cognitive (cf. Bloch, 1994).

Galton's hypothesis also influenced the psychometric tradition of mental-ability testing. For instance, Binet's (1890) original conceptualization of intelligence was hierarchical in nature (une echelle metrique de l'intelligence), with sensory and perceptual information processing at the lower level of the hierarchy and the reconstruction of previously perceived external stimuli in memory and the operations on the reinstated mental representations at the upper level of the hierarchy. However, Binet's empirical work was restricted to the upper level. Traces of the influence from this senses-intelligence hypothesis can also be found in the development of neuropsychological tests designed for assessing neurological symptoms and premorbid intelligence. Various sensory tasks (i.e., visual, auditory and tactile perception) have been included along with more cognitively-oriented tests (i.e., memory, logical reasoning, and verbal comprehension tasks) in major neuropsychological tests, such as the Luria-Nebraska Neuropsycological Battery (Golden, Hammeke, \& Purisch, 1979) and the Halstead-Reitan Neuropsychological Battery (Maffei, Luoni, Vita, \& Bertrando, 1987). The inclusion of sensory tasks in these batteries reveals an implicit recognition of a potential association between sensory and cognitive abilities.

Taken together, due to the small (or moderate) magnitudes of the correlations between simple sensory tasks and measures of intelligence, Galton's senses-intelligence hypothesis has been largely ignored in the psychometric tradition of testing and measuring mental abilities. However, the underlying rationale of this hypothesis has been captured in some classical theories of cognitive development and in the designs of prominent neuropsychological batteries.

\section{Galton's Hypothesis and the Information-Processing Approach to Intelligence}

More recently, Galton's notion of a causal relation between sensory functioning and intelligence has been resurrected within the information-processing framework. This more mechanism-oriented approach to the study of cognition has motivated researchers to search for potential determinants for interindividual differences in intelligence at the level of elementary cognitive processing components (Carroll, 1974; Jensen, 1987). Consequently, the links between various indices of elementary cognitive processing (such as simple reaction time and choice reaction time) and psychometrically defined general intelligence have attracted renewed empirical and theoretical interest since the early 1970s (for an early review see Vernon, 1987). Perhaps the most basic among all has been the studies which investigated the relation between simple sensory tasks and intellectual functioning.

Auditory and Visual Sensory Information Processing and Intelligence. Among the different sensory modalities, the links between vision, audition and intelligence have been studied most often. At present, there are data documenting significant associations between intellectual functioning and basic indices of auditory and visual information processing, such as sensory speed (e.g., Deary, 1993; Deary, Caryl, Egan, \& Wright, 1989; Deary, Head ,\& Egan, 1989; Nettelbeck \& Young, 1990; Raz \& Willerman, 1985; Raz, Willerman, Ingmundson, \& Hanlon, 1983), sensory discrimination (Irwin, 1984; Lynn, Wilson, \& Gault, 1989; Raz, Moberg, \& Millman, 1990; Raz, Willerman, \& Yama, 1987; Watson, 1991) and sensory acuity (e.g., Baltes \& Lindenberger, 1997; Lindenberger \& 
Baltes, 1994; Salthouse, Hancock, Meinz, \& Hambrick, 1996; Granick, Kleban, \& Weiss, 1976). There is also some evidence for an increasingly strong connection between sensory and cognitive functioning as people age. For instance, Baltes and Lindenberger (1997) examined the relative strength of the sensory-cognitive link across the entire adult-life span, and found a $20 \%$ age-related increase in the predictive power of auditory and visual acuity in accounting for individual differences in fluid intelligence. Salthouse et al. (1996) also reported that a large proportion of age-related variance in measures of processing speed, working memory, associative learning and concept identification was shared with measures of visual acuity.

A Few Studies on Tactile Sensory Processing and Intelligence. Data documenting the relationships between basic information processing in other sensory modalities and intelligence are much more scarce and indirect (cf. Carroll, 1993, p. 546). This is due in part to the fact that sensory deficits in other modalities usually do not affect an individual's daily functioning to the same extent as auditory or visual deficits do. However, because the sense of touch can be a surrogate channel of communication to compensate for deficits in vision and hearing, there has been a surge of interest in tactile sensation in the field of sensory research in recent years (e.g., Van-Doren, Gescheider, \& Verrillo, 1990; Verrillo, 1993). Some researchers have developed tactile tasks as nonverbal intelligence tests for the blind (e.g., Brand, Pieterse,\& Frost, 1986; Duncan, Wiedel, Prickett,\& Vernon, 1989) or as sub-scales of neuropsychological batteries (e.g., Golden, Hammeke,\& Purisch, 1979; Maffei et al., 1987), and others have developed tactile stimulation programs for enhancing cognitive development of pre-term infants (e.g., Adamson-Macedo, Dattani, Wilson, \& de Carvalho, 1993; de Roiste \& Bushnell, 1996). However, apart from these more specific and applied efforts, only a handful of studies (i.e., Finlayson \& Reitan, 1976; Horton \& Alana, 1990; Reed, 1967; Roberts, Stankov, Pallier, \& Dolph, 1997; Rosén, Lundberg, Dahlin, Holmberg, \& Karlson, 1994) have more directly investigated the relation between tactile sensory processing and intelligence. Reed (1967) reported a relationship between lateralized tactile-perceptual errors and reading achievement. Finlayson and Reitan (1976) found that children (age 12-14 years) who performed more poorly on tactile-perceptual tasks also performed significantly less well on a reading task and a category-learning task. In a more recent study on individual differences in the level of nerve repair after hand surgery, Rosén et al. (1994) found that $17 \%$ of the variance in verbal learning and $13 \%$ of the variance in visual spatial abilities were related to individual differences in the level of nerve repair indicated by the hand's functional sensibility (measured by tactile shape/dimension identification) after surgery. Horton and Alana (1990) examined the relations between the MiniMental State (MMS) test and subscales of the Luria-Nebraska Neuropsychological Battery (LNNB) within a small sample of demented old adults (mean age $=70.3$ ). After controlling for age, the subscale of tactile performance in the LNNB continued to be significantly correlated with the MMS. However, one should note that a subscale of the MMS involves copying a figure, hence this association might not originate entirely from the cognitive involvement entailed in the tactile performance and the MMS test. Shared variance between the tasks at the level of motor coordination may have added additional contribution to this link. Very recently, Roberts et al. (1997) conducted a very thorough factor-analytic study involving young participants (mean age $=23.59, S D=6.66$ ) to investigate the role of tactile-kinesthetic performance in the structure of intelligence that was defined by 
more than 25 cognitive variables. Seven tactile-kinesthetic variables, ranging from tactual texture, tactual shape, to finger counting, finger writing and tactual bead memory were included. Roberts et al.'s (1997) results showed that the tactile-kinesthetic abilities correlated highly with broad visualization and fluid intelligence, but less so with crystallized intelligence. However, as pointed out by the authors (Roberts et al., 1997, p. 119), the tactile-kinesthetic battery used in this study was somewhat biased in favor of relatively complex processes, rather than tactile information processing at a more sensory level. Two of the tasks, finger counting and tactual bead memory have direct analogues (i.e., letter counting and visual bead memory) in the traditional psychometric domains. The tactile texture task is the most "sensory-based" and the least complex task in Roberts et al.'s (1997) battery.

In summary, although Galton's hypothesis of a path from "good senses" to "good sense" has been pretty much discarded from the psychometric studies of intelligence for a long time, it has left impacts on theories of cognitive development and the tradition of neuropsychological measurements. Motivated by the information-processing approach to cognition, some researchers have re-evaluated Galton's hypothesis and found supporting evidence for links between intelligence and auditory and visual sensory information processing. However, information documenting such an intersystemic (i.e., cross-domain) relationship involving cognitive functioning and sensory processing in other modalities is very limited. In the case of the tactile sense, although there have been a handful of studies, these studies either involved only neurological patients, children or young adults. In addition, most of these previous studies did not include sufficient measures of intellectual functioning to identify a general factor of intelligence. In one case within which a complete cognitive battery was included, the tactile-kinesthetic tasks examined were slightly biased towards complex processes that entail cognitive involvement, such as tactile counting or memory (e.g., Roberts et al., 1997). Thus far, no study has explored the relation between more basic tactile sensory information processing and intelligence in heterogeneous samples of the healthy middle-aged adult population. Given this current state, the major purpose of this study is to fill this lacunae by using tactile tasks that are less biased towards complex processes to extend the research on the sensory-cognitive link to the tactile sense in middle-aged adults.

\section{METHOD}

\section{Participants}

In order to obtain a heterogeneous sample, 183 individuals aged 30 to 51 years were recruited by a survey research institute to take part in a three-session study on sensory and intellectual functioning in middle adulthood. Research participants were paid $20 \mathrm{DM}$ per session. Of the original 183 participants, two participants who had medical histories of epilepsy and head injury and one who lacked data on visual acuity were not included in the analyses. In addition, one other participant who, during testing, showed general difficulties in understanding task instructions of various tests in the cognitive battery and some additional tests (i.e., the Positive and Negative Affect Scales, Watson, Clark, \& Tellegen, 1988; the listening and reading span tasks, Daneman \& Carpenter, 1980) was also excluded from the analysis ${ }^{1}$. As a result, the effective sample consisted of 179 participants (86 men and 
93 women). At the time of study, 96 of the participants were between 30 to 40 years old, and 83 of them were between 41 to 51 years old. Four participants were left-handed, three were ambidextrous and the remaining 172 individuals were right-handed. Direction of handedness was assessed with a questionnaire including seven items (i.e., writing, throwing a ball, using scissors, brushing teeth, and etc.) taken from the Edinburgh Handedness Inventory (Oldfield, 1971).

\section{Tactile Measures and Testing Procedures}

Three different tactile measures (i.e., light pressure threshold sensitivity, texture discrimination and part-whole matching with curvature discrimination) were administered. Although two of these three tactile measures involves tactile discrimination, none of them involve counting or memory as did in some of the measures used by Roberts et al. (1997). These three measures often serve as neurological assessments of tactile sensory function in clinical settings (e.g., Nahm, Tranel, Damasio, \& Damasion, 1993; Mielke, Novak \& Mackinnon, 1996; Nebes, 1971 a, b; Rosén et al., 1994). They are, however, rarely used by cognitive or differential psychologists. Hence, in the following we provide detailed descriptions of each of the three measures.

Pressure Threshold Sensitivity. Diminishing sensitivity to pressure is commonly regarded as an early symptom of neurological impairment in the tactile modality. Therefore, the assessment of light-pressure threshold is perhaps the most common sensory examination in neurological clinical practice. In this study, light-pressure thresholds were measured with the Semmes-Weinstein Aesthesiometer (SWA; Semmes, Weinstein, Ghent, \& Teuber, 1960). The SWA consists of 20 nylon monofilaments of uniform 3.8-cm length and of increasing thickness (diameters range from 0.06 to $1.14 \mathrm{~mm}$ ). Each monofilament is mounted at the end of a 14-cm plastic stick holder and is numbered to represent log-10 of the force in gram.

Procedure. Examination of tactile threshold sensitivity took place in a quiet room. The participant's hand was covered with a rectangular wooden box (length $42 \mathrm{~cm}$, width $24 \mathrm{~cm}$, height $20 \mathrm{~cm}$ ), which was open towards the experimenter, and contained a semicircle-shaped hole $(7 \mathrm{~cm}$ in radius) towards the participant. The hole allowed the participant to put one hand inside the box, but prevented the participant from any visual input regarding the tactile stimulation. Following clinical practice, dorsal and palmar sides of the nailbed of the middle finger were examined. The nailbed was chosen to avoid areas with hair growth and callus. Pressure stimulation started with the dominant hand. Each of the 20 nylon-monofilament stimuli was slowly applied with enough pressure to create a 45 degree bend in the filament, and was held in that position for 1.5 seconds. The participant was asked to indicate whether he or she felt the stimulus by saying "yes" or "no." If the participant did not respond within three seconds, the same stimulus was applied a second time. Testing started with the monofilament of lowest force pressure (i.e., the thinnest filament with a $0.06 \mathrm{~mm}$ diameter), and ascended in single steps until three successive touches had been reported. At this point, testing continued in descending order beginning with the next lowest monofilament (i.e., the second above the ascending threshold) in single steps until three successive "no" responses were reported. 
Texture Discrimination. The second tactile measure was assessed by a roughness (texture) discrimination task. Texture perception is a basic function of the tactile system. Hence, tasks involving the discrimination of surface texture have been used to examine the capacity and limitation of an individual's tactile sensory functions. Head (1920) was among the first to suggest the use of roughness discrimination for clinical purposes. More recently, roughness discrimination task has also been included in neuropsychological tests as a subtest of tactile object recognition (Reed \& Caselli, 1994; Reed, Lederman, \& Klatzky, 1990). Sandpaper or emery cloth set with graded levels of roughness is often used as experimental stimuli for roughness discrimination (e.g., Decarlo, 1994; Lederman, Jones, \& Segalowitz, 1984; Stevens \& Harris, 1962). In this study, an ordered set of sandpaper of the following grit numbers was used: $40,60,80,100,120,150,180$ and 220 . The sandpaper was cut into $18-\mathrm{cm}$ squares. The grit numbers refer to the number of openings per inch in the screen employed to sift the particles. The fewer the openings, the larger the particles. Hence sandpaper with small grit number is rougher. There were five levels of roughness discrimination, from zero (no difference) to a four-step difference (e.g., sandpaper with grit number 60 paired with sandpaper with grit number 150 ).

Procedure. Each of the two stimuli of a given pair was successively presented to the participant. With randomized presentation order, each pair of stimuli was presented for a total of 20 times. The participants were instructed to feel the roughness of a pair of sandpaper using their index and middle fingers, and to judge whether the two pieces of sandpaper were of a same or different level of roughness. The participants were instructed to use as much time as they needed to make the judgment. For most participants, two to three seconds were enough for making a response. The wooden box described in the previous section was used to prevent visual input. Left and right hands were tested separately. Half of the participants were randomly assigned to start with the right hand, and the remaining half to start with the left hand.

Part-Whole Matching with Curvature Discrimination. The third tactile measure was assessed by the arc-circle task. This task was developed by Nebes (1971 a, b) to measure tactual perception of part-whole relations and intermodal (i.e., tactile-visual) matching. The arc-circle matching task has been mostly used in clinical settings to investigate the relationship between handness and hemispheric functioning and the role of the amygdala in cross-modal association (e.g., Hardyck, 1977; Hartje, Reul, \& Willmes, 1988; Nahm et al., 1993). The stimuli were plastic circles with outer diameters of 3,4 and $5 \mathrm{~cm}$ (the thickness of the circles was $2 \mathrm{~mm}$ ) and arcs of $80^{\circ}, 120^{\circ}, 180^{\circ}, 280^{\circ}$ and $360^{\circ}$ that were corresponding to each circle size. The participant's task was to match the arc to the circle of which it was a segment.

Procedure. We modified Nebes' (1971a) original tactile-visual cross-modal matching task to be a tactile-tactile within-modal matching task by asking the participants to feel both the arc and the circles with their index finger (in Nebes' original task, the three circles were constantly kept in front of the participant for visual inspection). Thus, our participants first felt the arc with their fingers, and then were allowed to feel the circles and to select the circle that the arc is a segment of. The participants were allowed as much time as they needed for making a response. Again, in order to prevent visual input, both the arcs and the circles were hidden from the participant's sight. Left and right hand were tested separately. 
Half of the participants were randomly assigned to start with the right hand, and the remaining half to start with the left hand.

\section{Visual and Auditory Acuity}

For comparison purposes, the participants' visual and auditory acuity were also assessed. Close visual acuity was measured separately for the two eyes in Snellen decimal units at reading distance. Two standard reading tables, one with Landolt rings and the other with printed text, were used (Geigy, 1977). Participants were tested without optical corrections (i.e., glasses) as well as with optical corrections if available. Analyses were based on the better values of the two. Auditory acuity was measured with a Bosch ST-20-1 pure-tone audiometer using headphones. Hearing thresholds were measured separately for the right and left ears at eight different frequencies. Testing started with the better ear. For participants who did not know which ear was their better one, testing started with the right ear. Within ears, frequencies were tested in the following order: $1.00,2.00,3.00,4.00,6.00$, $8.00,0.50$, and $0.25 \mathrm{kHz}$ (see Lindenberger \& Baltes, 1994 for more details of these two tasks).

\section{Cognitive Test Battery}

In order to broadly assess individual differences in intellectual functioning and to define a general factor of intelligence, we employed a comprehensive cognitive test battery (Baltes \& Lindenberger, 1997; Lindenberger \& Baltes, 1994; Lindenberger, Mayr, \& Kliegl, 1993). Briefly, the battery consists of 14 tests measuring five intellectual abilities: (a) perceptual speed (measured by Digit Letter, Digit Symbol Substitution and Identical Pictures); (b) reasoning (Figural Analogies, Letter Series and Practical Problems); (c) memory in the sense of episodic memory or short-term acquisition and retrieval (Activity Recall, Memory for Text and Paired Associates); (d) knowledge (Practical Knowledge, Spot-a-Word and Vocabulary); (e) and word fluency (Animal Names and Letter "S"). A detailed description of the battery is provided elsewhere (cf. Lindenberger \& Baltes, 1997, Lindenberger et al., 1993).

\section{Procedure}

Testing of sensory and cognitive functioning was distributed over three sessions. Auditory and visual acuity as well as epidemiological background information were individually assessed during the first session. The cognitive battery was administered in small groups of three to five in the second session. The three tactile tasks were administered individually in the third session, starting with the light pressure sensitivity task, followed by the roughness discrimination and the arc-circle tasks.

\section{RESULTS}

We first report descriptive statistics of the measures of sensory and cognitive functioning, followed by results from correlational analyses done in the measurement space and structural equation modeling analyses done in the latent space. Table 1 shows the means and standard deviations of all measures used in the analyses. The pressure threshold task 
Table 1. Descriptive Statistics for Tactile, Auditory, Visual and Cognitive Variables

\begin{tabular}{|c|c|c|c|c|c|c|c|}
\hline \multicolumn{8}{|c|}{ Domain of Functioning } \\
\hline \multicolumn{2}{|c|}{ Tactile } & \multicolumn{2}{|c|}{ Auditory } & \multicolumn{2}{|c|}{ Visual } & \multicolumn{2}{|c|}{ Cognitive } \\
\hline Variable & $\begin{array}{c}M \\
(S D)\end{array}$ & Variable & $\begin{array}{c}M \\
(S D)\end{array}$ & Variable & $\begin{array}{c}M \\
(S D)\end{array}$ & Variable & $\begin{array}{c}M \\
(S D)\end{array}$ \\
\hline $\begin{array}{l}\text { SWA } \\
\text { (Palm) }\end{array}$ & $\begin{array}{l}3.10 \\
(.34)\end{array}$ & $\begin{array}{l}.25 \mathrm{kHz} \\
\text { (left) }\end{array}$ & $\begin{array}{l}10.55 \\
(6.35)\end{array}$ & $\begin{array}{l}\text { Text } \\
\text { (Close) }\end{array}$ & $\begin{array}{c}.89 \\
(.24)\end{array}$ & $\begin{array}{l}\text { Digit } \\
\text { Symbol }\end{array}$ & $\begin{array}{c}62.12 \\
(11.66)\end{array}$ \\
\hline $\begin{array}{l}\text { SWA } \\
\text { (Dorsal) }\end{array}$ & $\begin{array}{l}3.08 \\
(.32)\end{array}$ & $\begin{array}{l}.50 \mathrm{kHz} \\
\text { (left) }\end{array}$ & $\begin{array}{c}9.59 \\
(5.71)\end{array}$ & $\begin{array}{l}\text { Landolt } \\
\text { (Close) }\end{array}$ & $\begin{array}{c}.79 \\
(.22)\end{array}$ & Digit Letter & $\begin{array}{l}126.22 \\
(23.72)\end{array}$ \\
\hline Rough1 & $\begin{array}{c}5.66 \\
(2.35)\end{array}$ & $\begin{array}{l}1.00 \mathrm{kHz} \\
\text { (left) }\end{array}$ & $\begin{array}{l}10.28 \\
(5.63)\end{array}$ & & & $\begin{array}{l}\text { Ident. } \\
\text { Pictures }\end{array}$ & $\begin{array}{l}28.98 \\
(3.85)\end{array}$ \\
\hline Rough2 & $\begin{array}{c}9.8 \\
(2.47)\end{array}$ & $\begin{array}{l}2.00 \mathrm{kHz} \\
\text { (left) }\end{array}$ & $\begin{array}{l}12.25 \\
(7.06)\end{array}$ & & & $\begin{array}{l}\text { Paired } \\
\text { Assoc. }\end{array}$ & $\begin{array}{l}12.44 \\
(3.68)\end{array}$ \\
\hline Rough3 & $\begin{array}{l}13.56 \\
(1.93)\end{array}$ & $\begin{array}{l}3.00 \mathrm{kHz} \\
\text { (left) }\end{array}$ & $\begin{array}{l}11.94 \\
(8.62)\end{array}$ & & & $\begin{array}{l}\text { Memory } \\
\text { for Text }\end{array}$ & $\begin{array}{l}6.77 \\
(1.24)\end{array}$ \\
\hline $\operatorname{Arc120}$ & $\begin{array}{l}2.38 \\
(.52)\end{array}$ & $\begin{array}{l}4.00 \mathrm{kHz} \\
\text { (left) }\end{array}$ & $\begin{array}{c}14.31 \\
(10.86)\end{array}$ & & & $\begin{array}{l}\text { Activity } \\
\text { Recall }\end{array}$ & $\begin{array}{c}7.02 \\
(1.84)\end{array}$ \\
\hline Arc180 & $\begin{array}{l}2.55 \\
(.57)\end{array}$ & $\begin{array}{l}6.00 \mathrm{kHz} \\
\text { (left) }\end{array}$ & $\begin{array}{c}18.17 \\
(12.95)\end{array}$ & & & $\begin{array}{l}\text { Figural } \\
\text { Analogies }\end{array}$ & $\begin{array}{l}14.94 \\
(3.84)\end{array}$ \\
\hline \multirow[t]{9}{*}{$\operatorname{Arc} 280$} & $\begin{array}{l}2.74 \\
(.57)\end{array}$ & $\begin{array}{l}8.00 \mathrm{kHz} \\
\text { (left) }\end{array}$ & $\begin{array}{c}19.95 \\
(13.94)\end{array}$ & & & $\begin{array}{l}\text { Letter } \\
\text { Series }\end{array}$ & $\begin{array}{l}11.11 \\
(3.66)\end{array}$ \\
\hline & & $\begin{array}{l}.25 \mathrm{kHz} \\
\text { (right) }\end{array}$ & $\begin{array}{l}11.45 \\
(7.34)\end{array}$ & & & $\begin{array}{l}\text { Practical } \\
\text { Reasoning }\end{array}$ & $\begin{array}{l}10.04 \\
(2.21)\end{array}$ \\
\hline & & $\begin{array}{l}.50 \mathrm{kHz} \\
\text { (right) }\end{array}$ & $\begin{array}{l}10.41 \\
(5.62)\end{array}$ & & & Categories & $\begin{array}{c}28.52 \\
(5.11)\end{array}$ \\
\hline & & $\begin{array}{l}1.00 \mathrm{kHz} \\
\text { (right) }\end{array}$ & $\begin{array}{l}11.88 \\
(5.65)\end{array}$ & & & $\begin{array}{l}\text { Word } \\
\text { Beginning }\end{array}$ & $\begin{array}{l}19.82 \\
(4.58)\end{array}$ \\
\hline & & $\begin{array}{l}2.00 \mathrm{kHz} \\
\text { (right) }\end{array}$ & $\begin{array}{l}12.35 \\
(6.83)\end{array}$ & & & Vocabulary & $\begin{array}{l}22.38 \\
(4.63)\end{array}$ \\
\hline & & $\begin{array}{l}3.00 \mathrm{kHz} \\
\text { (right) }\end{array}$ & $\begin{array}{l}11.19 \\
(7.34)\end{array}$ & & & $\begin{array}{l}\text { Spot-a- } \\
\text { Word }\end{array}$ & $\begin{array}{l}25.53 \\
(4.14)\end{array}$ \\
\hline & & $\begin{array}{l}4.00 \mathrm{kHz} \\
\text { (right) }\end{array}$ & $\begin{array}{l}13.59 \\
(9.35)\end{array}$ & & & $\begin{array}{l}\text { Practical } \\
\text { Knowl. }\end{array}$ & $\begin{array}{l}19.06 \\
(2.05)\end{array}$ \\
\hline & & $\begin{array}{l}6.00 \mathrm{kHz} \\
\text { (right) }\end{array}$ & $\begin{array}{c}17.66 \\
(11.21)\end{array}$ & & & & \\
\hline & & $\begin{array}{l}8.00 \mathrm{kHz} \\
\text { (right) }\end{array}$ & $\begin{array}{c}19.71 \\
(12.99) \\
\end{array}$ & & & & \\
\hline
\end{tabular}

yielded two measures, SWA applied to either the dorsal or the palmar side of the nailbed. In order to avoid floor and ceiling performance, analyses of the two tactile discrimination tasks were restricted to the three intermediate levels of difficulty. The three variables taken from the texture discrimination task were one-, two-, and three-step differences in roughness. Responses to the intermediate degrees of the arc (i.e., $120^{\circ}, 180^{\circ}$ and $280^{\circ}$ arcs) were first averaged across circle size, and then taken as indicators of the Arc-Circle task. Variables of auditory acuity were measured in decibel units $(\mathrm{dB})$ for both ears at eight different frequencies. Indicator variables for close visual acuity were measured in Snellen decimal units, and referred to as printed text or Landolt rings. Finally, measures from the 14 cognitive tests, ranging from digit symbol substitution to practical knowledge, formed the set of indicators for cognitive ability 
Computing Composite Variables. Unit-weighted composite scores based on standardized indicators were computed for all the tasks. Because the cognitive and the auditory variables were identical to the ones used by Lindenberger and Baltes (1994), we followed their procedures to compute composite scores for these two classes of measures. Three composite variables of fluid intelligence broadly defined (i.e., perceptual speed, memory and reasoning) and two for the broad crystallized domains (i.e., knowledge and fluency) were computed. In addition, we also computed a composite score of general cognitive functioning $(g)$ that was based on the standardized indicators of perceptual speed, memory, reasoning, knowledge, and fluency. In order to reduce skewness and kurtosis in measures of auditory acuity (mean krutosis estimate $=4.74$ and mean skewness estimate $=1.72$ ), the raw scores of auditory acuity were first log-transformed. The first two hearing indicator variables were unit-weighted composites of the measures from the six low-frequency (i.e., .25 to $4.00 \mathrm{kHz}$ ) conditions within each ear (i.e., one variable for the right ear and another variable for the left ear). The third variable was the unit-weighted composite of the highfrequency (i.e., 6.00 to $8.00 \mathrm{kHz}$ ) measures across both ears. The two indicator variables for vision were unit-weighted composites of the scores assessed with the Landolt rings and the printed text.

An exploratory factor analysis using maximum likelihood extraction followed by oblique rotation was used to examine the data structure of the tactile measures. The resulting pattern of factor loadings is shown in Table 2. Clearly, the tactile variables formed three distinct factors, one for each task. Based on the factor patterns, we therefore formed three unit-weighted composite variables of tactile pressure sensitivity (SWA), texture discrimination (Roughness) and part-whole matching (Arc-Circle). As indicated by the factor correlations reported in Table 2, the factor of tactile pressure sensitivity did not correlate with the other two tactile factors; whereas the two factors of tactile discrimination (i.e., roughness discrimination and the Arc-Circle task) were related to each other. Because the main effect of gender was significant for the measure of pressure sensitivity, $F(1,175)=$ $48.06, p<.000$, the effect of gender was first partialed out before forming the composite score. The following correlational and structural modeling analyses were based on the unitweighted composites described in this section.

Table 2. Factor Pattern Matrix of Tactile Variables

\begin{tabular}{lccc}
\hline \multicolumn{1}{c}{ Factor } & & & \\
\hline Variable Name & I & II & III \\
Arc120 & .02 & .00 & .58 \\
Arc180 & .00 & -.07 & .85 \\
Arc280 & -.04 & .07 & .65 \\
Rough1 & -.06 & .75 & .04 \\
Rough2 & .08 & .94 & .03 \\
Rough3 & .10 & .77 & .025 \\
SWA (Dorsal) & .97 & -.10 & .00 \\
SWA (Palmar) & .46 & .05 & .00 \\
& & Factor Correlations & \\
& & II & III \\
& I & 0.01 & 0.03 \\
& II & - & 0.21 \\
\hline
\end{tabular}


Table 3. Correlations of Sensory and Cognitive Variables with Age

\begin{tabular}{ccccccc}
\hline \multicolumn{8}{c}{ Sensory Variables } \\
Age & Arc-Circle & Roughness & SWA & Hearing & Vision & \\
& $-.18^{*}$ & .01 & $-.28^{* *}$ & $-.26^{* *}$ & $-.45^{* *}$ & \\
\hline \multicolumn{8}{c}{ (Discrimination Measures) } & (Threshold Measures) \\
\hline & Cerceptual & & & & \\
& Speed & Memory & Reasoning & Knowledge & Fluency & $g$ \\
Age & $-.18^{*}$ & $-.18^{*}$ & $-.23^{* *}$ & .05 & .07 & $-.17^{*}$ \\
& & (Fluid Measures) & (Crystallized Measures) & & \\
\hline
\end{tabular}

\section{Analyses in the Measurement Space}

Negative Age Trends. Despite the relatively restricted age range in our sample, significant negative age trend were observed in some of the variables (see Tables 3 ). The magnitudes of these correlations were compared using Meng, Rosenthal, and Rubin's (1992) tests for dependent correlation coefficients. Overall, close visual acuity showed the strongest negative age trend (i.e., using one-tail test, $z$ values for pairwise comparisons of dependent $r$ between vision and all other variables were all significant at the .05 or $.01 \mathrm{lev}$ els). In the sensory domain, the roughness measure was the only one which did not show any age trend. A two-group contrast comparing the mean correlation with age of the three sensitivity measures (i.e., auditory, visual and pressure sensitivity) with the mean correlation with age of the two discrimination measures (i.e., roughness discrimination and partwhole matching) showed that the sensitivity measures were more strongly related to age than the discrimination measures $(z=3.82)$. In the cognitive domain, the abilities from the broad fluid domain (i.e., speed, memory, and reasoning) showed stronger negative age trends $(z=5.05)$ than the abilities from the crystallized domain (i.e., knowledge and fluency). The finding that the three intellectual abilities from the broad fluid domain (also known as the "mechanics" of cognition, Baltes, 1987) are more negatively related to age than the two crystallized abilities is consistent with earlier findings in a different age range (70 to 103 years) using the same battery (Lindenberger \& Baltes, 1997).

Intercorrelations. Table 4 shows the intercorrelations between the sensory and cognitive variables both before and after controlling for the effect of age (values in parentheses). Overall, controlling for age did not affect the correlations between the two tactile discrimination variables and cognitive functioning. Owing to the stronger correlations with age, the correlations between visual acuity and measures of fluid intelligence were attenuated the most after the effect of age was partialed out. Among the five sensory variables, scores from the two discrimination tasks showed stronger correlations with the cognitive measures than the three threshold scores. In fact, a two-group contrast comparing the mean age-partialed correlation between the three sensitivity measures and $g$ with the mean agepartialed correlation between the two discrimination measures (i.e., roughness discrimination and part-whole matching) and $g$ showed that the discrimination measures were more strongly related to cognitive functioning than the threshold measures $(z=2.3)$. Although 
Table 4. Intercorrelations Between Sensory and Cognitive Variables Before and After Controlling for Age.

\begin{tabular}{lcccccc}
\hline \multicolumn{7}{c}{ Cognitive Variables } \\
\hline Sensory & Perceptual & & & \\
Variables & Speed & Memory & Reasoning & Knowledge & Fluency & $g$ \\
\hline Arc-Circle & $.22^{* *}$ & $.23^{* *}$ & $.29^{* *}$ & $.32^{* *}$ & $.18^{* *}$ & $.33^{* *}$ \\
& $\left(.20^{* *}\right)$ & $\left(.20^{* *}\right)$ & $\left(.26^{* *}\right)$ & $\left(.32^{* *}\right)$ & $\left(.17^{* *}\right)$ & $\left(.31^{* *}\right)$ \\
Roughness & .08 & $.25^{* *}$ & $.17^{*}$ & $.23^{* *}$ & .11 & $.22^{* *}$ \\
& $(.08)$ & $\left(.25^{* *}\right)$ & $\left(.18^{*}\right)$ & $\left(.23^{* *}\right)$ & $(.11)$ & $\left(.23^{* *}\right)$ \\
SWA & .09 & $.20^{* *}$ & .04 & .13 & $.19^{* *}$ & $.18^{*}$ \\
Hearing & $(.04)$ & $\left(.16^{*}\right)$ & $(-.03)$ & $(.12)$ & $\left..18^{* *}\right)$ & $\left(.14^{*}\right)$ \\
& $.15^{*}$ & $.14^{* *}$ & $.16^{*}$ & .10 & .05 & $.15^{*}$ \\
Vision & $(.11)$ & $(.10)$ & $(.10)$ & $(.09)$ & $(.03)$ & $(.11)$ \\
& $.17^{*}$ & .13 & $.18^{*}$ & $.16^{*}$ & $.16^{*}$ & $.19^{*}$ \\
& $(.10)$ & $(.06)$ & $(.08)$ & $\left(.16^{*}\right)$ & $(.08)$ & $\left(.13^{*}\right)$ \\
\hline
\end{tabular}

Note: Values in parentheses refer to age-partialed correlations.

slightly lager in absolute magnitude, the age-partialed correlations between scores of the Arc-Circle task and $g$ did not differ significantly from the correlation between the ability of roughness discrimination and $g(z=1.26)$. However, the Arc-Circle measure did correlate with $g$ more strongly than the correlations between $g$ and pressure sensitivity (one-tail test $z=1.89$ ), auditory acuity (one-tail test $z=2.31$ ) and visual acuity (one-tail test $z=1.96$ ).

\section{Analyses in the Latent Space}

To some extent, analyses done in the measurement space could be affected by measurement error. In order to correct for potential differences in measurement reliability of the different measures, age-partialed scores were further analyzed in latent space using structural equation modeling (EQS; Bentler, 1989; LISREL, Jöreskog \& Sörbom, 1991). Following Bentler's (1989) suggestion, the Persons $\times$ Variables input data matrix was inspected for the contribution of individual variables and persons to deviations from normality. Two participants with very high contributions to multivariate kurtosis were excluded from further analyses. After excluding these two participants, univariate skewness and kurtosis estimates did not exceed $|1|$ for most variables, except for Activity Recall ( kkewness $=-1.3$; kurtosis $=2.01$ ), Figural Analogies (kurtosis $=1.25$ ) and the level-3 measure of roughness discrimination (skewness $=-1.1$; kurtosis $=1.1$ ).

A Structural Model of Tactile Factors Predicting g. In order to examine the sensory-cognitive link, a structural model relating interindividual differences in cognitive and tactile sensory functioning was constructed using structural equation modeling (SEM). In most applications of SEM, the observed variables are conceived as indicators or manifestations of some underlying (or latent) causal constructs ${ }^{2}$. The conceptualization of latent causal constructs implies that variations in the latent constructs would be reflected in the observed variables, and the theoretical causal directions are from the latent constructs to the indicator variables. Conventional path-diagram representations of the relations between the latent constructs and their corresponding observed variables are single-headed arrows pointing towards the indicator variables from the latent factors. With respect to the 


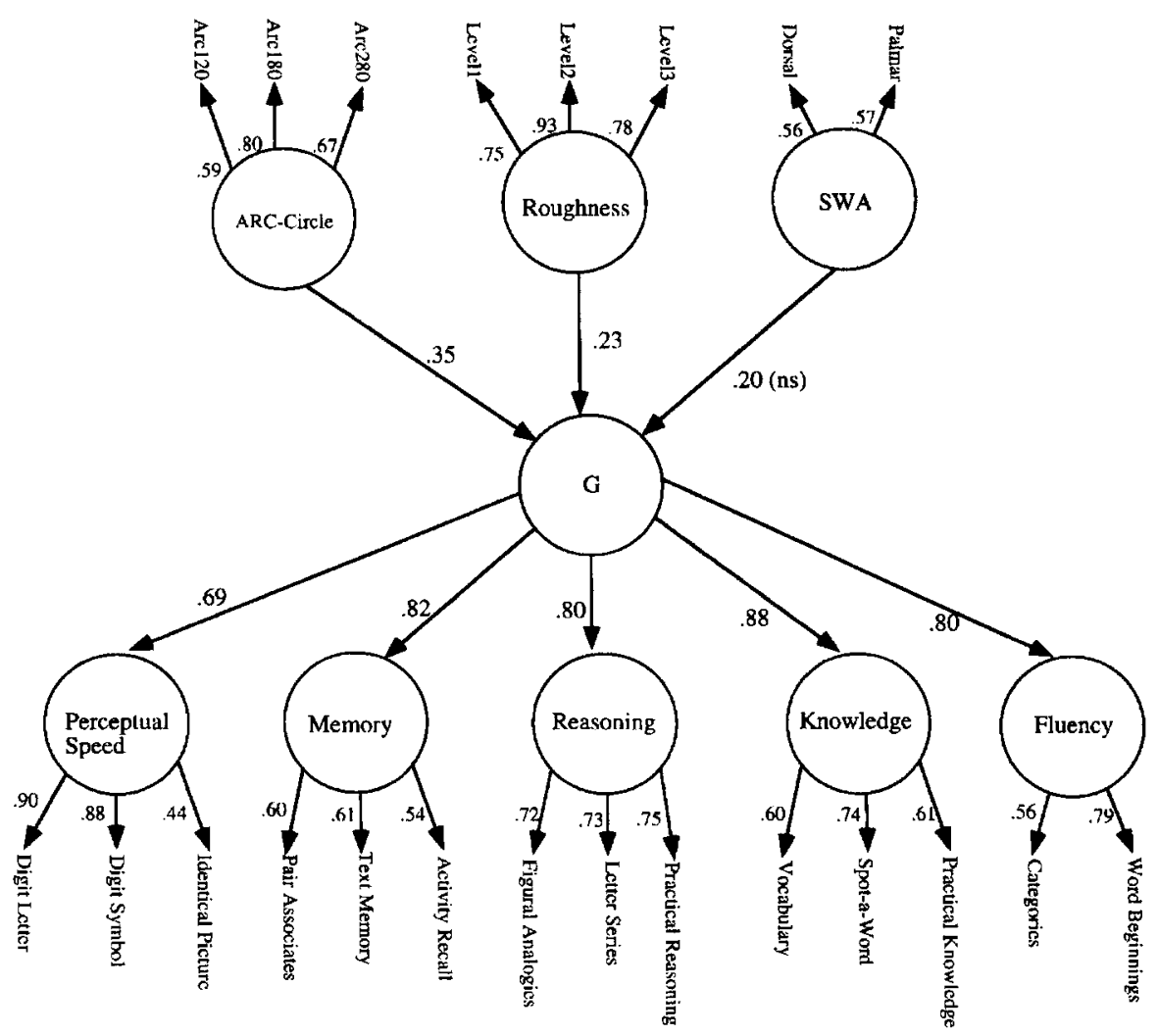

Figure 1. A path model of three tactile facors predicting $g$

cognitive measures in the present data set, SEM identified a hierarchical structure with a second-order latent $g$ factor of general cognitive performance that was again indicated by five first-order latent cognitive factors (i.e., perceptual speed, memory, reasoning, knowledge and fluency). A structure involving three latent tactile factors (i.e., ARC-Circle, Roughness and SWA) that were indicated by their corresponding observed variables was identified for measures in the domain of tactile sensory functioning. The intersystemic relationships between cognitive functioning and the three tactile factors were examined by allowing predictive paths from the three tactile factors to $g$. This is analogous to performing a regression analysis involving regressing $g$ on the tactile variables in measurement space; however, the advantage of analyzing these relations using SEM in the latent space is that the results are not biased by differences in measurement reliability. The model depicted by the path diagram presented in Figure 1 fitted the data quite well, $\chi^{2}=247.03$, $d f=196, N=177, \mathrm{CFI}=0.95, \mathrm{NNFI}=0.96$. Of particular interest here is the relative strength of the predictive paths of the three tactile factors to $g$. In line with the findings obtained with unit-weighted composites in the measurement space, the factor of tactile 


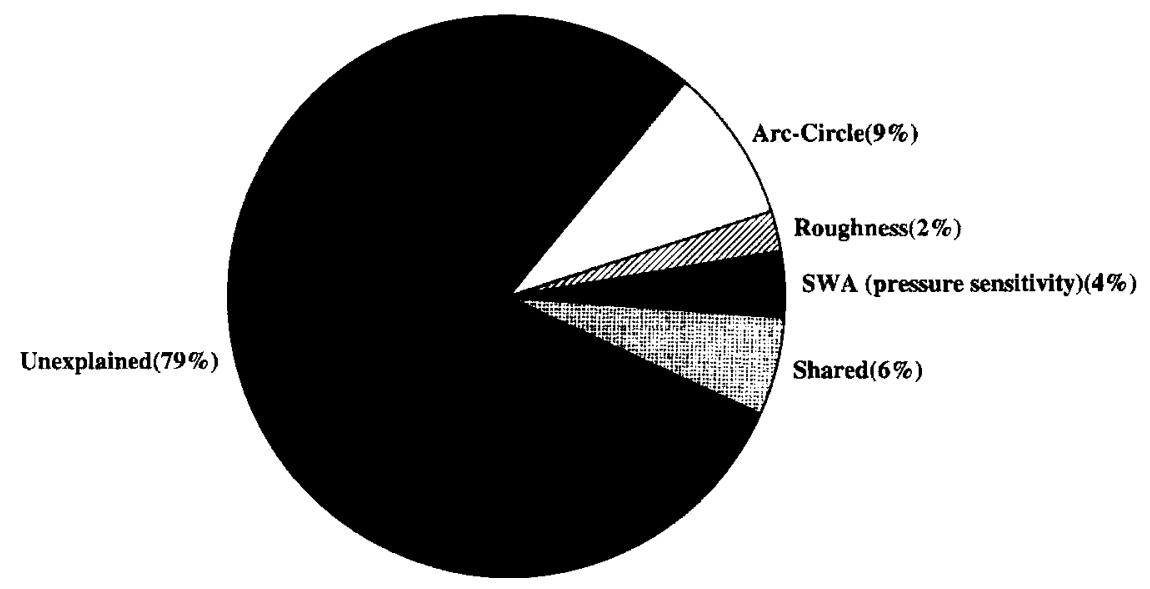

Figure 2. Percentages of total variance in $g$ that are uniquely explained by the three tactile factors. The amounts of unique variance related to the Arc-Circle and the Roughness factors are statistically greater than zero. The amount of unique variance attributed to the SWA factor is, however, not significantly greater than zero $\left(\Delta \chi^{2}(1, N=177)=2.8, p=.10\right)$, due to a wider confidence interval for the maximum likelihood estimate.

threshold sensitivity had the weakest predictive strength. Specifically, this path was not estimated to be significant, while the other two were.

Commonality Analysis in Latent Space. The unique and shared contributions of the three tactile factors in predicting individual differences in intellectual functioning were further examined using methods of variance decomposition (Hertzog, 1989; Jernstedt, 1980; Pedhazur, 1982). We regressed $g$ on all seven possible predictor combinations in the latent space (i.e., arc-circle alone, roughness alone, SWA alone, arc-circle and roughness, arc-circle and SWA, roughness and SWA, and arc-circle, roughness and SWA). In terms of simple effects, the arc-circle factor accounted for $15.2 \%$ of the variance in $g$, the roughness factor for $7.5 \%$ and the SWA factor for $3.8 \%$. Taken together, all three tactile factors accounted for $20.8 \%$ of the variance in $g$. In terms of unique effects, $9 \%$ of the total variance (43\% of the explained variance) in $g$ was uniquely accounted for by the arc-circle factor. This amount differed significantly from zero, $\Delta \chi^{2}(1, N=177)=12.05, p<.001$. About $2 \%$ of the total variance in $g$ ( $11 \%$ of the explained variance) was uniquely predicted by the roughness factor. This amount also differed significantly from zero, $\Delta \chi^{2}(1, N=177)=$ $6.32, p<.01$. And lastly, about $4 \%$ of the total variance in $g$ ( $18 \%$ of the explained variance) was uniquely related to the factor of threshold sensitivity. However, due to a larger confidence interval for the maximum likelihood estimate, this amount did not differ significantly from zero, $\Delta \chi^{2}(1, N=177)=2.8, p=.10$. Figure 2 presents the proportions of variance in intelligence that were uniquely explained by the three tactile factors. Hence results from the commonality analysis showed again that the two discrimination measures, but not the threshold measure, had significant unique contributions in predicting general intelligence. 
Comparing the Predictive Strengths of Discrimination and Sensitivity Measures.

One consistent pattern in the results of the preceding analyses is that the two measures of tactile discrimination were better predictors of $g$ than simple measures of tactile, auditory or visual threshold sensitivity. In order to compare and contrast the predictive strengths of the discrimination and sensitivity measures, a series of structural models were fitted to the data. Table 5 summarizes the relevant model comparisons. A reference model with freely estimated regression paths from all sensory factors to $g$ (Model 1) yielded a good approximation to the data (model statistics are listed in Table 5). We then tested the null hypothesis that all sensory predictors were of equal predictive strength by constraining parameters of these paths to be equal (Model 2). Comparing this second model with the reference model showed that the null hypothesis could be rejected, because equality constraints on all five paths led to a significant decrement in fit. Having rejected the null hypothesis, we then compared the differences in the predictive strengths of the sensory predictors. We first tested whether the two tactile discrimination measures were of equal pre-

Table 5. Summaries of Structural Models With Different Equality

Constraints on the Predictive Paths.

\begin{tabular}{|c|c|c|c|c|c|c|}
\hline Model & Commentary & $\chi^{2}\left(\Delta \chi^{2}\right)$ & $d f$ & $p$ & $C F I$ & $N N F I$ \\
\hline $\begin{array}{l}1) \\
\text { Free }\end{array}$ & $\begin{array}{l}\text { All sensory paths to } g \text { were } \\
\text { free to be estimated }\end{array}$ & 371.7 & 310 & .01 & .96 & .96 \\
\hline \multirow[t]{2}{*}{$\begin{array}{l}\text { (2) } \\
\text { ALL }\end{array}$} & $\begin{array}{l}\text { Constraining all sensory } \\
\text { paths to be equal } \\
\text { (i.e., arc = roughness = SWA } \\
=\text { hearing = vision) }\end{array}$ & 387.8 & 314 & .003 & .95 & .96 \\
\hline & (2)-(1) Comparison & 16.13 & 4 & $<.01$ & & \\
\hline \multirow[t]{2}{*}{$\begin{array}{l}(3) \\
\text { Tactile } 1\end{array}$} & $\begin{array}{l}\text { Constraining the two tactile } \\
\text { discrimination paths to be } \\
\text { equal (i.e., arc = roughness) }\end{array}$ & 372.1 & 311.01 & .96 & .96 & \\
\hline & (3)-(1) Comparison & .4 & 1 & $>.5$ & & \\
\hline \multirow[t]{2}{*}{$\begin{array}{l}(4) \\
\text { Tactile } 2\end{array}$} & $\begin{array}{l}\text { Constraining two tactile } \\
\text { factors to be equal (i.e., arc = } \\
\text { SWA) }\end{array}$ & 385.3 & 311 & .003 & .95 & .96 \\
\hline & (4)-(1) Comparison & 13.6 & 1 & $<.001$ & & \\
\hline \multirow[t]{2}{*}{$\begin{array}{l}(5) \\
\text { Tactile } 3\end{array}$} & $\begin{array}{l}\text { Constraining two tactile } \\
\text { factors to be equal (i.e., } \\
\text { roughness = SWA) }\end{array}$ & 382.6 & 311 & .003 & .95 & .96 \\
\hline & (5)-(1) Comparison & 10.9 & 1 & $<.001$ & & \\
\hline \multirow[t]{2}{*}{$\begin{array}{l}\text { (6) } \\
\text { Threshold }\end{array}$} & $\begin{array}{l}\text { Constraining the three } \\
\text { sensory sensitivity paths to be } \\
\text { equal (i.e., SWA = hearing = } \\
\text { vision) }\end{array}$ & 371.9 & 312 & .01 & .96 & .96 \\
\hline & (6)-(1) Comparison & .2 & 2 & $>.9$ & & \\
\hline \multirow[t]{2}{*}{$\begin{array}{l}\text { (7) } \\
\text { Discrimination - } \\
\text { Threshold }\end{array}$} & $\begin{array}{l}\text { Constraining the two } \\
\text { discrimination paths to be } \\
\text { equal, and the three sensory } \\
\text { to be equal (i.e., arc = } \\
\text { roughness; SWA = hearing = } \\
\text { vision) }\end{array}$ & 373.6 & 313 & .01 & .96 & .96 \\
\hline & $\begin{array}{l}\text { (7)-(1) Comparison } \\
\text { (7)-(2) Comparison }\end{array}$ & $\begin{array}{c}1.9 \\
-142\end{array}$ & 3 & $>3$ & & \\
\hline
\end{tabular}




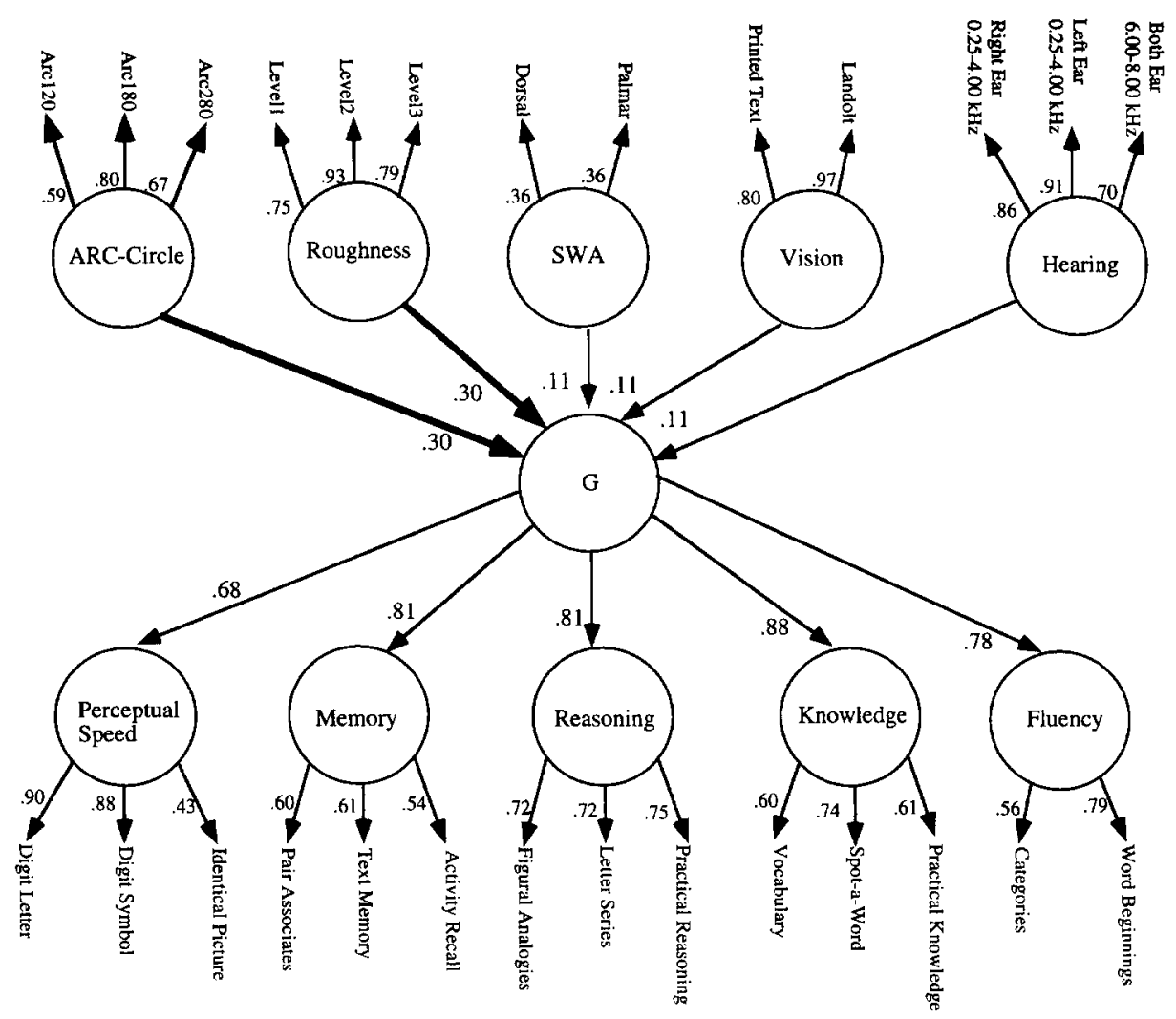

Figure 3. A path model comparing the strengths of the predictive paths from the sensory discrimination factors and the sensory sensitivity factors to $g$.

dictive strength. As it is shown in Table 5, constraining these two paths to be equal (Model 3 in Table 5) did not lead to a significant reduction in model fit. This indicates that the two sensory discrimination tasks did not differ significantly in their predictive strengths. Within the tactile measures, we further tested whether the predictive strength of each of the two tactile discrimination measures differed from that of the tactile sensitivity measure. Setting the paths from the Arc-Circle factor and the SWA factor to $g$ to be equal (Model 4 ) did lead to a significant decrement in fit, indicating that the predictive strength of the ArcCircle factor is significantly stronger than the factor of simple tactile sensitivity. Similarly, setting the paths from the roughness factor and the SWA factor to $g$ to be equal (Model 5 ) also led to a significant decrement in fit. On the other hand, when the paths from the three sensory sensitivity measures to $g$ were constrained to be equal (Model 6), the model fit was not affected. This indicates that the three measures of sensory sensitivity did not differ reliably in their predictive strengths. Finally, we compared the predictive strengths of the discrimination and the threshold measures by constraining the path parameters of the two discrimination measures to be equal, and the path parameters of the three threshold measures to be equal (i.e., arc-circle $=$ roughness, $\mathrm{SWA}=$ hearing $=$ vision). This model with 
Table 6. Correlation Matrices of $g$, Sensory Discrimination and Sensory Sensitivity in Different Age and Ability Groups

\begin{tabular}{|c|c|c|c|c|c|}
\hline \multicolumn{6}{|c|}{ Groups Defined by Age } \\
\hline \multicolumn{3}{|c|}{30 to 40 years old $(N=96)$} & \multicolumn{3}{|c|}{41 to 51 years old $(N=83)$} \\
\hline & $\mathrm{g}$ & Discrim. & & $\mathrm{g}$ & Discrim. \\
\hline Discrim. & $.23 *$ & - & Discrim. & $.49^{* *}$ & - \\
\hline Sensitivity & .17 & .05 & Sensitivity & $.29 * *$ & .07 \\
\hline \multicolumn{6}{|c|}{ Groups Defined by Ability Level } \\
\hline \multicolumn{3}{|c|}{ High Ability Group $(N=38)($ top 20\%) } & \multicolumn{3}{|c|}{ Low Ability Group $(N=36)($ bottom $20 \%)$} \\
\hline & $\mathrm{g}$ & Discrim. & $\mathrm{g}$ & Discrim. & \\
\hline Discrim. & .09 & - & Discrim. & .20 & - \\
\hline Sensitivity & -0.005 & -.08 & Sensitivity & .25 & -.11 \\
\hline
\end{tabular}

both constraints implemented simultaneously (Model 7) continued to fit the data as well as the reference model (compare Models 1 and 7). At the same time, the fit of this model was significantly better than the fit of the model in which all the sensory- $g$ paths had been constrained to be equal (compare Models 2 and 7). Taken together, Model 7 provides the most accurate and parsimonious structural representation of the data (see Figure 3). In agreement with results from previous analyses, the two discrimination measures were more predictive (estimated path coefficients $=.30$ ) of $g$ than the three threshold measures (estimated path coefficients $=.11$ ).

\section{The Strength of the Sensory-Cognitive Link in Relation to Other Variables}

Thus far, our results suggest that the type of the sensory task, either discrimination or simple sensitivity, has an effect on the strength of the sensory-cognitive link. Although it is not the main objective of this study to answer questions concerning what are the potential factors that might modulate the strength of the senses-intelligence link proposed by Galton, the effects of two additional variables were examined. Given that some studies have shown that aging might strengthen the sensory-cognitive link (e.g., Baltes \& Lindenberger, 1997; Lindenberger \& Baltes, 1994; Salthouse et al., 1996) and that other studies (e.g., Deary, Egan, Gibson, Austin, Brand, \& Kellaghan, 1996; Detterman \& Daniel, 1989; Legree, Pifer, \& Grafton, 1996) have reported findings supporting Spearman's dedifferentiation hypothesis (i.e., ability structure tends to be more correlated at the low ability level), we further analyzed the links between $g$ and the sensory measures with respect to age and ability level. With respect to age, the participants were separated into a younger subsample ( 30 to 40 years old) and an older subsample ( 41 to 51 years old). With respect to ability level, a high-ability subsample (the top $20 \%$ ) and a low-ability subsample (the bottom $20 \%$ ) were defined based on the levels of $g$.

Age and the Sensory-Cognitive Link. The top part of Table 6 shows the correlations between $g$ and the composite variables of the two sensory discrimination measures and the three sensory sensitivity measures in the two age groups. The intersystemic correlations between $g$ and the sensory variables were stronger in the older group. Separate prin- 
cipal component analyses of the three variables (e.g., $g$, discrimination and sensitivity) showed that the first unrotated principal component of the older subsample accounted for $53.1 \%$ of the variance, while the first unrotated principal component of the younger subsample only accounted for $43.8 \%$ of the variance. This finding indicates a less differentiated ability structure in the older subsample.

Ability Level and the Sensory-Cognitive Link. The bottom part of Table 6 shows the correlations between $g$ and the composite variables of the two sensory discrimination measures and the three sensory sensitivity measures in the two subsamples of high and low ability. The intersystemic correlations between $g$ and the sensory variables were larger in the low-ability subsample. Principal component analyses of the correlation matrices of the two subsamples showed that the first unrotated principal component of the low-ability group accounted for $42.5 \%$ of the variance, while the first unrotated principal component of the high-ability subsample only accounted for $37.4 \%$ of the variance. This finding is suggestive of a less differentiated ability structure in the low-ability subsample.

\section{Discussion}

In this article, we investigated the link between tactile sensory processing and cognitive functioning in middle adulthood ( 30 to 51 years old) using two tactile discrimination and one tactile sensitivity measures. The results reported here extend recent findings of a sensory-cognitive link found in auditory and visual modalities to the tactile modality within a sample of healthy middle-aged adults. All together, the three tactile variables accounted for $20.8 \%$ of the interindividual differences in intelligence. Measures from the tactile modality were at least as highly correlated with $g$ as measures of auditory and visual acuity. In addition, our results also revealed that sensory discriminations tasks are more highly correlated with $g$ than tasks measuring simple sensory acuity. In the following, we discuss these results in more details with respects to a few candidate factors (i.e., task complexity, age and ability level) that might modulate the strengths of the correlation between sensory and cognitive functioning and some theoretical implications.

\section{Task Complexity, Age, Ability Level and the Sensory-Cognitive Link}

The finding that the two measures of sensory discrimination are more predictive of intellectual functioning than measures of simple sensory acuity is in line with previous results regarding task complexity. It is usually found that more cognitively demanding tasks correlate more highly with $g$ (e.g., Jensen, 1993; Roznowski, 1993; Vernon \& Weese, 1993). Among the tactile tasks, pressure threshold sensitivity can be viewed as analogous to auditory or visual acuity in the sense that all three are basic measures of absolute sensory threshold which entail very limited cognitive involvement. Texture discrimination and part-whole matching are cognitively more complex than threshold sensitivity because they are measures of relative sensory threshold and involve processes of comparison and judgment.

In addition to the complexity of the task, results in the last section of our analyses are also suggestive of two additional factors that could modulate the strength of the sensorycognitive link. The finding that sensory threshold measures did not correlate highly with $g$ during the middle adulthood is not surprising. Previous studies have shown that the 
strength of the link between sensory and cognitive functioning increases as a function of aging (e.g., Baltes \& Lindenberger, 1997; Lindenberger \& Baltes, 1994). When we reexamined the link between vision and hearing and $g$ in the 30-51 year-old segment of the Baltes and Lindenberger's (1997) sample, we found that the correlations between $g$ and visual $(r=.219)$ and auditory acuity $(r=.162)$ were comparable to our results. In addition, results from our last set of analyses suggest that the strength of the sensory-cognitive link increases even with the very limited age range represented in this study. Specifically, when we divided our sample into younger ( 30 to 40 years old) and older (41 to 51 years old) subsamples, we found that correlations between sensory variables and $g$ were generally larger in the older subsample. In terms of the amount of variance accounted for by the first unrotated principal component in older and younger subsamples, the magnitude of this age difference attained $9.3 \%$. Similarly, results from subdividing the sample into groups of high and low ability based on the composite $g$ scores also showed that the ability structure tended to be more highly intercorrelated in the low ability level. The first unrotated principal component of the low-ability group accounted for $5.1 \%$ more of the variances in $g$ than that of the high-ability group. Albeit preliminary and not backed up by formal inferential statistical tests, these results are at least consistent with previous findings of an age-related increase in the strength of the link between sensory and cognitive functioning (e.g., Baltes \& Lindenberger, 1997; Salthouse et al., 1996) and an effect of dedifferentiation in the ability structure at low ability level (e.g., Deary et al., 1996; Detterman \& Daniel, 1989; Legree et al., 1996).

\section{A Multi-level Approach to the Understanding of the Sensory-Cognitive Link}

Besides Galton's original senses-intelligence hypothesis, one other explanation known as the common-cause hypothesis (Baltes \& Lindenberger, 1997; Lindenberger \& Baltes, 1994) has recently been proposed to account for the age-related increase in the correlation between sensory and cognitive functioning. Briefly, the essence of the common-cause hypothesis is that low-level sensory processing and high-level cognitive functioning are both expressions of a third common factor, namely, the efficacy of neural information processing in the central nervous system. As aging compromises brain efficacy which in turn affects both sensory and cognitive processes, performances in these two domains become increasingly intercorrelated.

Although both Galton's (1883) original senses-intelligence hypothesis and the common-cause hypothesis aim at explaining the intersystemic relationship between sensory and cognitive functioning, the emphases of these two hypotheses differ in two respects. First, while Galton's senses-intelligence hypothesis deals generally with the relation between the senses and cognitive abilities, the common-cause hypothesis focuses specifically on age-related changes in the strength of the sensory-cognitive link. Second, Galton's senses-intelligence hypothesis directly emphasizes the effect of sensory functioning on intellectual ability, whereas the common-cause hypothesis emphasizes the effect of brain functioning jointly affecting both sensory and cognitive performance. With respect to the second point, even if one holds Galton's original view of a direct causal effect of sensory functioning on intellectual ability, to date some empirical evidence suggests that this intersystemic link does not arise from sensory information processing at the peripheral level. For instance, Lindenberger and Baltes (1996) found that peripheral reductions in visual and 
auditory acuity did not lead to general decrements in intellectual performance. Similarly, the finding of a relationship between tactile sensory information processing and cognitive functioning reported in this study also indirectly suggests that peripheral sensory factors have no (or little) contribution to the sensory-cognitive link. The efficacy of tactile sensory functioning does not have direct peripheral effect on how well the individuals could read and see the test items in the cognitive test battery, and hence could not directly affect test performance. In addition, the finding that sensory discrimination measures yield superior prediction of $g$ over simple threshold measures also suggests that it is not the absolute sensory threshold which gives major contribution to the sensory-cognitive link, rather it is the relative sensory threshold in detecting differences between perceptual stimuli which has more contribution. Given that the sensory-cognitive link is not likely to originate from sensory information processing at the peripheral level, it might arise from signal-detection mechanisms of neural information processing at the brain level, as suggested by the common-cause hypothesis.

In our view, with respect to the empirical relation between sensory and cognitive functioning, the common-cause hypothesis is well in concert with Galton's senses-intelligence hypothesis; with respect to the level of theorizing, however, the common-cause hypothesis is proposed at a different level. No direct causal link is drawn between sensory and cognitive information processing, rather the intersystemic link is proposed to arise from general mechanisms governing neural information processing in both domains of functioning at the brain level. In a sense, one might suggest that the level of theorizing at which the common-cause hypothesis is situated could offer explanations for Galton's hypothesis from the biological level. Indeed, Galton originally argued that the more perceptive the senses are of differences, the "wider" the field upon which an individual's judgment and intelligence can act. However, it was not specified as to what mechanisms might affect the "sensitivity" of the senses when dealing with variabilities in perceptual stimuli. It is reasonable to propose that the sensitivity of the senses are determined by the underlying biological processes which regulate the fidelity of neural information processing.

In a recent theoretical attempt to computationally link aging-induced deterioration in neurotransmitter systems and the dedifferentiation of ability structure in old age, $\mathrm{Li}$ and Lindenberger (in press) demonstrated that varying the responsivity (or sensitivity) of units in artificial neural networks could simulate interindividual differences in the fidelity of neural information processing. Moreover, a network responding less sensitively to minor variations in the input signals would undergo a greater amount of intra-network variability across processing time steps, which in turn leads to a greater degree of inter-network variability in a group of networks and stronger intercorrelations between the networks' performance in different tasks. Additional benchmark cognitive aging phenomena can also be computationally implemented using a similar manipulation (e.g., Li, Lindenberger \& Frensch, 1996). Although these computational inquiries were at a rather general and abstract level, without specifying the exact details of different types of sensory and cognitive processing, they do theoretically suggest that the fidelity of neural information processing that is fundamental to both sensory and cognitive processes might be the biological mechanism for Galton's senses-intelligence link. 


\section{CONCLUSION}

We have demonstrated that tactile sensory information processing is related to cognitive functioning, and that the strength of the tactile-cognitive link is compatible to the strength of the auditory-cognitive and visual-cognitive links. These results along with the finding of a substantial amount of common variance shared between fluid intelligence and a battery of seven tactile-kinesthetic measures reported by Roberts et al. (1997) together suggest that when investigating the relationship between sensory and cognitive functioning, the tactile modality should not be ignored. Although the magnitude of the correlations are within the moderate range, our results also suggest that the strength of the sensory-cognitive link is influenced by task complexity, age and, perhaps, ability level. Systematic experimental or quasi-experimental variations of these factors may be a potential fruitful strategy for further research on Galton's sense-intelligence hypothesis. In addition, it is useful to examine the sensory-cognitive link both interindividually and intraindividually (e.g., Li et al., 1998). Thus far, almost all reports (including this present study) on the sensory-cognitive link were based on interindividual differences. Correlations between these two domains of functioning were computed across rather than within persons. However, in order to better understand the mechanisms of why and how does sensory functioning correlate with cognitive functioning, intraindividual variability which more directly indicates fluctuations in within-person functioning when reliably measured may be of more direct relevance. Taking the cross-level approach of cognitive neuroscience to the relationship between sensory and cognitive functioning will provide us new possibilities to relate Galton's senses-intelligence link with its potential biological underpinnings.

Acknowledgements: We thank A.R. Jensen, P.A. Vernon and an anonymous reviewer for their helpful comments on an earlier version of this article.

\section{NOTES}

1. Including this participant in the analyses overall did not weaken the relations between cognitive functioning and most measures reported in this article, except slightly lowering the correlations between the composite score of general cognitive performance and the indicators of roughness discrimination (from $r=0.22, p<0.05$ to $r=0.20, p<0.05$ or from $r=0.23, p<0.05$ to $r=0.20, p<0.05$ for the age-partialed correlation) and auditory acuity (from $r=0.15, p<0.05$ to $r=0.11, p=0.08$, or from $r=0.11, p=0.08$ to $r=0.07, p=0.19$ for the agepartialed correlation).

2. Detailed discussions about two kinds of variable systems (i.e., latent causal construct and emergent construct) that can be conceptualized in SEM are presented in Bollen and Lennox (1991), and Cole, Maxwell, Arvey, and Salas (1993).

\section{REFERENCES}

Adamson-Macedo, E.N., Dattani, I., Wilson, A., \& de Carvalho, F.A. (1993). A small sample follow-up study of children who received tactile stimulation after pr-term birth: Intelligence and achievements. Journal of Reproductive and Infant Psychology, 11, 165-168.

Abelson, A.R. (1911). The measurement of mental ability of backward children. British Journal of Psychology, 4, 268-314.

Baltes, P. B. (1987). Theoretical propositions of life-span developmental psychology: On the dynamics between growth and decline. Developmental Psychology, 23, 611-626. 
Baltes, P.B., \& Lindenberger, U. (1997). Emergence of a powerful connection between sensory and cognitive functions across the adult lifespan: a new window to the study of cognitive aging? Psychology and Aging, $12,12-21$.

Bentler, P.M. (1989). EQS. Structural equations manual. Los Angeles: BMDP Statistical Software.

Binet, A. (1890). Perceptions d'enfants. Revue philosophique, 15, 528-611

Bloch, H. (1994). Intermodal participation in the formation of action in the infant. In D. J. Lewkowicz \& R. Lickliter (Eds.), The Development of Intersensory Perception (pp. 309-334). Hillsdale, NJ: LEA.

Bollen, K., \& Lennox, R. (1991). Conventional wisdom on measurement: A structural equation perspective. Psychological Bulletin, 110, 305-314.

Brand, H.J., Pieterse, M.J., \& Frost, M. (1986). Reliability and validity of the Ohwaki-Hoh's Tactile Block Design test for the blind. Psychological Reports, 58, 375-380.

Burt, C. (1909-1910). Experimental tests of general intelligence. British Journal of Psychology, 3, 94-177.

Carey, N. (1914-1915). factors in the mental processes of schoolchildren. British Journal of Psychology, 7, 453490.

Carey, N. (1915-1917). factors in the mental processes of schoolchildren: II. On the nature of specific mental factors. British Journal of Psychology, 8, 70-92.

Carroll, J.B. (1974). Psychometric tests as cognitive tasks: A new "structure of intellect." Princeton, NJ: Educational Testing Service.

Carroll, J.B. (1993). Human Cognitive Abilities: A Survey of Factor-Analytic Studies. New York: Cambridge University Press.

Cole, D.A., Maxwell, S.E., Arvey, R., \& Salas, E. (1993). Multivariate group comparisons of variable systems: MANOVA and structural equation modeling. Psychological Bulletin, 114, 174-184.

Daneman, M., \& Carpenter, P.A. (1980). Individual differences in working memory and reading. Journal of Verbal Learning and Verbal Behavior, 19, 450-466.

Deary, I.H. (1993). Inspection time and WAIS-R IQ subtypes: A confirmatory factor analysis study. Intelligence, 17, 223-236

Deary, I.J. (1994). Sensory discrimination and intelligence: Postmortem or resurrection? American Journal of Psychology, 107, 95-115.

Deary, I.J., Caryl, P.G., Egan, V., \& Wright, D. (1989). Visual and auditory inspection time: Their interrelationship and correlations with intelligence in high ability subjects. Personality and Individual Differences, 10 , 525-533.

Deary, I.J., Head, B., \& Egan, V. (1989). Auditory inspection time, intelligence and pitch discrimination. Intelligence, $13,135-148$.

Deary, I.J., Egan, V., Gibson, G.J., Austin, E.J., Brand, C.R., Kellaghan, T. (1996). Intelligence and the differentiation hypothesis. Intelligence, $23,105-132$.

DeCarlo, L.T. (1994). A dynamic theory of proportional judgment: Context and judgment of length, heaviness, and roughness.

de Roiste, A., \& Bushnell, I.W.R. (1996). Tactile stimulation: Short- and long-term benefits for pre-term infants. British Journal of Developmental Psychology, 14, 41-53.

Detterman, D.K., \& Daniel, M.H. (1989). Correlations of mental tests with each other and with cognitive variables are highest for low IQ groups. Intelligence, 13, 349-359.

Duncan, E., Wiedel, J.W., Pricket, H.T., \& Vernon, M. (1989). The tactile TONI: A possible new performance IQ test for blind adults? Journal of Visual Impairment and Blindness, 33, 510-511.

Eysenck, H.J. (Ed.). (1982). A model for intelligence. New York: Springer-Verlag

Finlayson, M.A., \& Reitan, R.M. (1976). Tactile-perceptual functioning in relation to intellectual, cognitive and reading skills in younger and older normal children. Developmental Medicine and Child Neurology, 18, $442-446$.

Galton, F. (1883). Inquiries into human faculty and its development. London: MacMillan.

Geigy, J.R. (1977). Wissenschfatliche Tabellen [Scientific Tables]. Basel, Switzerland: J. R. Geigy AG.

Gibson, E.J. (1969). Principles of perceptual learning and development. New York: Appleton-Century-Crofts.

Golden, C.J., Hammeke, T.A., Purisch, A.D. (1979). Diagnostic validity of a standardized neuropsychological battery derived from Luria's neuropsychological tests. Clinical Neuropsychology, 1, 1-7.

Granick, S., Kleban, M.H., Weiss, A.D. (1976). Relationship between hearing loss and cognition in normally hearing aged persons. Journal of Gerontology, 31, 434-440.

Hardyck, C. (1977). Handness and part-whole relationships: A replication. Cortex, 13, 177-183. 
Hartje,-W., Reul, J., \& Willmes, K. (1988). Left hemispheric interference with nonverbal performance in aphasics: Comparison with data from split-brain studies. Brain and Cognition, 8, 137-146.

Head, H. (1920). Studies in neurology. New York: Oxford University Press.

Herrnstein, R.J., \& Boring, E.G. (1965). A source book in the history of psychology. Cambridge, MA: Harvard University Press.

Hertzog, C. (1989). Influences of cognitive slowing on age differences in intelligence. Developmental Psychology, 25, 636-651.

Hilgard, E.R. (1987). Psychology in America: A historical survey. San Diego, CA: Harcourt Brace Jovanovich.

Horton, A.M., \& Alana, S. (1990). Validation of the Mini-Mental State Examination. International-Journal-ofNeuroscience, 53, 209-212

Hunt, E. (1980). Intelligence as an information-processing concept. British Journal of Psychology, 71, 449-474.

Irwin, R.J. (1984). Inspection time and its relation to intelligence. Intelligence, 8, 47-65.

Jensen, A.R. (1987). Process differences and individual differences in some cognitive tasks. Intelligence, 11,107 136.

Jensen, A.R. (1993). Why is reaction time correlated with psychometric $g$ ? Current Directions in Psychological Science, 2, 53-56.

Jernstedt, G.C. (1980). Commonality analysis: Partitioning variance for multivariate prediction. Educational and Psychological Measurement, 40, 739-743.

Jöreskog, K.G., \& Sörbom, D. (1991). LISREL 7: A guide to the program and applications (2nd Ed.). Chicago: SPSS.

Lederman, S., Jones, B., Segalowitz, S. (1984). Lateral symmetry in the tactual perception of roughness. Canadian Journal of Psychology, 38, 599-609

Legree, P.J., Pifer, M.E., \& Grafton, F.C. (1996). Correlations among cognitive abilities are lower for higher ability groups. Intelligence, $23,45-57$.

Li, S.-C., \& Lindenberger, U. (in press). Cross-level Unification: A computational exploration of the link between deterioration of neurotransmitter systems and dedifferentiation of cognitive abilities in old age. In L.-G. Nilsson \& H. Markowitsch (Eds.), Neuroscience of Memory. Toronto: Hogrefe \& Huber Publishers.

Li, S.-C., Aggen, S. H., Nesselroade, J.R., \& Baltes, P.B. (1998). Revisiting the link between memory and sensorimotor functioning in old age via intraindividual variability: The MacArthur Successful Aging Studies. Manuscript submitted for publication.

Li, S.-C., Lindenberger, U., \& Frensch, P. (1996). In search of an integrated framework of cognitive aging: A computational exploration of the link between processing efficiency and brain catecholamines. Manuscript submitted for publication.

Lindenberger, U., \& Baltes, P. B. (1994). Sensory functioning and intelligence in old age: A strong connection. Psychology and Aging, 9, 339-355.

Lindenberger, U., \& Baltes, P.B. (1996). The age-related dynamic between sensory and intellectual functioning: Testing the role of peripheral sensory factors. Paper presented at the 1996 Cognitive Aging Conference, Atlanta, GA.

Lindenberger, U. \& Baltes, P.B. (1997). Intellectual functioning in old and very old age. Cross-sectional results from the Berlin Aging Study. Psychology and Aging, 12, 410-432.

Lindenberger, U., Mayr, U., \& Kliegl, R. (1993). Speed and intelligence in old age. Psychology and Aging, 8, 207-220.

Lynn, R., Wilson, R.G., \& Gault, A. (1989). Simple musical tests as measures of Spearman's g. Personality and Individual Differences, 10, 25-28.

Maffei, C., Luoni, P., Vita, A., \& Bertrando, P. (1987). The Luria-Nebraska Neuropsychological Battery in schizophrenic disorders: Relationships to neuromorphological, intellectual and educational variables. New Trends in Experimental and Clinical Psychiatry, 3, 25-34.

Meng, X.I., Rosenthal, R., \& Rubin, D.B. (1992). Comparing correlated correlation coefficients. Psychological Bulletin, 111, 172-175.

Mielke, K., Novak. C., Mackinnon S. (1996) Hand sensibility measures used by therapists. Annual Review of Plastic Surgery, 36: 292-296.

Nahm, F.K.D., Tranel, D., Damasio, H., \& Damasio, A.R. (1993). Cross-modal associations and the human amygdala. Neuropsychologia, 31, 727-744.

Nettelbeck, T., \& Young, R. (1990). Inspection time and intelligence in 7-yr-old children: A follow-up. Personality and Individual Differences, 11, 1283-1289. 
Nebes, R.D. (1971a). Superiority of the minor hemisphere in commissurotomized man for the perception of partwhole relations. Cortex, 7, 333-349.

Nebes, R. D. (1971b). Handedness and the perception of the part-whole relationship. Cortex, 7, 350-356.

Oldfield, R.C. (1971). The assessment and analysis of handedness: The Edinburgh Inventory. Neuropsychologia, 9, 97-113.

Piaget, J. (1952). The Origins of Intelligence in Children. New York: International University Press.

Pedhazur, E.J. (1982). Multiple regression in behavioral research. New York: Holt.

Raz, N., Moberg, P.J., \& Millman, D. (1990). Effects of age and age-related differences in auditory information processing on fluid and crystallized intelligence. Personality and Individual Differences, 11, 1147-1152.

Raz, N., \& Willerman, L. (1985). Aptitude-related differences in auditory information processing: Effects of selective attention and tone duration. Personality and Individual Differences, 6, 299-304.

Raz, N., Willerman, L., Ingmundson, P., \& Hanlon, M. (1983). Aptitude-related differences in auditory recognition masking. Intelligence, 7, 71-90.

Raz, N., Willerman, L., \& Yama, M. (1987). On sense and senses: Intelligence and auditory information processing. Personality and Individual Differences, 8, 201-210.

Reed, C. (1967). Lateralized finger agnosia and reading achievement at ages 6 and 10. Child Development, 38, 213-220.

Reed, C., \& Caselli, R. (1994). The nature of tactile agnosia: A case study. Neuropsychologia, 32, 527-539.

Reed, C., Lederman, S.L., \& Klatzky, R.L. (1990). Haptic integration of planar size with hardness, texture, and planar contour. Canadian Journal of Psychology, 44, 522-545.

Roberts, R.D., Stankov, L., Pallier, G., \& Dolph, B. (1997). Charting the cognitive sphere: Tactile-kinesthetic performance within the structure of intelligence. Intelligence, 25, 111-148.

Rosén, D., Lundberg, G., Dahlin, L. B., Holmberg, J., Karlson, B. (1994). Nerve repair: Correlation of restitution of functional sensibility with specific cognitive capacities. Journal of Hand Surgery (British and European Volume), $19 B, 452-458$.

Roznowski, M. (1993). Measures of cognitive processes: Their stability and other psychometric and measurement properties. Intelligence, 17, 361-388.

Salthouse, T.A., Hancock, H.E., Meinz, E.J., \& Hambrick, D.Z. (1996). Interrelations of age, visual acuity, and cognitive functioning. Journal of Gerontology: Psychological Science, 51B, P317-P330.

Semmes, J., Weinstein, S., Ghent, L., \& Teuber, H.L. (1960). Somatosensory changes after brain wounds in man. Cambridge, MA: Harvard University Press.

Sharp, S.E. (1898-1899). Individual psychology: A study in psychological method. American Journal of Psychology, 10, 329-391.

Spearman, C. (1904). "General intelligence," objectively determined and measured. American Journal of Psychology, 15, 201-293.

Stevens, S.S., \& Harris, J.R. (1962). The scaling of subjective roughness and smoothness. Journal of Experimental Psychology, 64, 489-494.

Van-Doren, C.L., Gescheider, G.A., \& Verrillo, R.T. (1990). Vibrotactile temporal gap detection as a function of age. Journal of the Acoustical Society of America, 87, 2201-2206.

Vernon, P.A. (Ed.). (1987). Speed of information processing and intelligence. Norwood, NJ: Ablex Publishing Corporation.

Vernon, P.A., \& Weese, S.E. (1993). Predicting intelligence with multiple speed of information-processing tests. Personality and Individual Differences, 14, 413-419.

Verrillo, R.T. (1993). The effects of age on the sense of touch. In R. T. Verrillo (Ed.), Sensory Research: Multimodal Perspectives (pp. 285-298). Hillsdale, NJ: Lawrence Erlbaum.

Watson, B.U. (1991). Some relationships between intelligence and auditory processing. Journal of Speech and Hearing Research, 34, 621-627.

Watson, D., Clark, L. A., \& Tellegen, A. (1988). Development and validation of brief measures of positive and negative affect: The PANAS scales. Journal of Personality and Social Psychology, 54, 1063-1070.

Wissler, C. (1901). The correlation of mental and physical tests. Psychological Review, Monograph No. 3. 